\title{
LSD Acutely Impairs Fear Recognition and Enhances Emotional Empathy and Sociality
}

\author{
Patrick C Dolder', Yasmin Schmid', Felix Müller², Stefan Borgwardt ${ }^{2}$ and Matthias E Liechti*,I \\ 'Division of Clinical Pharmacology and Toxicology, Department of Biomedicine and Department of Clinical Research, University Hospital Basel, \\ Basel, Switzerland; '² Department of Psychiatry (UPK), University of Basel, Basel, Switzerland
}

\begin{abstract}
Lysergic acid diethylamide (LSD) is used recreationally and has been evaluated as an adjunct to psychotherapy to treat anxiety in patients with life-threatening illness. LSD is well-known to induce perceptual alterations, but unknown is whether LSD alters emotional processing in ways that can support psychotherapy. We investigated the acute effects of LSD on emotional processing using the Face Emotion Recognition Task (FERT) and Multifaceted Empathy Test (MET). The effects of LSD on social behavior were tested using the Social Value Orientation (SVO) test. Two similar placebo-controlled, double-blind, random-order, crossover studies were conducted using I00 $\mu \mathrm{g}$ LSD in 24 subjects and $200 \mu \mathrm{g}$ LSD in 16 subjects. All of the subjects were healthy and mostly hallucinogen-naive 25- to 65-year-old volunteers (20 men, 20 women). LSD produced feelings of happiness, trust, closeness to others, enhanced explicit and implicit emotional empathy on the MET, and impaired the recognition of sad and fearful faces on the FERT. LSD enhanced the participants' desire to be with other people and increased their prosocial behavior on the SVO test. These effects of LSD on emotion processing and sociality may be useful for LSD-assisted psychotherapy.

Neuropsychopharmacology (2016) 4I, 2638-2646; doi:I0.1038/npp.2016.82; published online 22 June 2016
\end{abstract}

\section{INTRODUCTION}

The classic serotonergic psychedelic/hallucinogen lysergic acid diethylamide (LSD) was widely studied in humans in the 1950s to 1970s. However, little to no clinical research on LSD has been conducted since then (Nichols, 2016; Passie et al, 2008). Today, LSD is again the focus of clinical investigations, including experimental studies in healthy subjects (Carhart-Harris et al, 2016,2015; Dolder et al, 2015b; Schmid et al, 2015; Strajhar et al, 2016), and clinical trials that evaluate LSD-assisted psychotherapy (Gasser et al, 2014). LSD that was administered only a few times decreased anxiety and increased quality of life over a period of 12 months in patients with anxiety associated with terminal illness (Gasser et al, 2015). The acute LSD experiences were hypothesized to lead to a restructuring of the person's emotional trust and situational understanding (Gasser et al, 2015). Similar to LSD, the serotonergic hallucinogen psilocybin and serotonin (5-hydroxytryptamine (5-HT)) releaser 3,4-methylenedioxymethamphetamine (MDMA; ecstasy) have been used to facilitate psychotherapy in clinical trials (Grob et al, 2011; Mithoefer et al, 2010; Oehen et al, 2013). Psilocybin reduced anxiety at 3 months

*Correspondence: Professor ME Liechti, Department of Biomedicine and Department of Internal Medicine, Division of Clinical Pharmacology and Toxicology, University Hospital Basel, Hebelstrasse 2, Basel CH-403I, Switzerland, Tel: +4I 6 I 32868 68, Fax: +4I 6I 26545 60,

E-mail: matthias.liechti@usb.ch

Received 4 March 2016; revised 26 April 2016; accepted I8 May 2016; accepted article preview online I June 2016 and additionally improved mood at 6 months after treatment in patients with advanced-stage cancer (Grob et al, 2011). Additionally, psilocybin was recently studied as a treatment for tobacco (Johnson et al, 2014) and alcohol (Bogenschutz et al, 2015) dependence. MDMA-assisted psychotherapy reduced symptoms of post-traumatic stress disorder at 2 months (Mithoefer et al, 2010), and the benefits of MDMA were reportedly sustained for several years (Mithoefer et al, 2013). These first findings from modern clinical studies with psychedelics and MDMA should be confirmed in larger trials. Exploring the mechanisms that may contribute to these beneficial and lasting effects after only a few administrations of the substances is also important.

Studies that use psychedelics and MDMA in healthy subjects are well suited to assess the mechanism of action of these substances. Both LSD and psilocybin appear to produce effects that last beyond the acute drug response in both patients and healthy subjects. Specifically, LSD increased optimism and trait openness at 2 weeks (Carhart-Harris et al, 2016), and psilocybin produced positive changes in attitudes, mood, and behavior at 2 (Griffiths et al, 2006) and 14 months (Griffiths et al, 2011) after administration. Psilocybin increased personality trait openness in participants who had 'mystical experiences' during their psilocybin session (MacLean et al, 2011). Therefore, some of the lasting beneficial effects appear to be associated with an acute psychedelic response, including a 'peak' or 'mystical' experience (Carhart-Harris et al, 2016; MacLean et al, 2011).

Both LSD and psilocybin are $5-\mathrm{HT}_{2 \mathrm{~A}}$ receptor agonists, and their psychedelic effects are mediated by $5-\mathrm{HT}_{2 \mathrm{~A}}$ 
receptor stimulation (Vollenweider et al, 1998). The longterm effects of LSD and psilocybin may be related to their psychedelic and $5-\mathrm{HT}_{2 \mathrm{~A}}$ receptor activation properties. In contrast to the psychedelics LSD and psilocybin, MDMA is considered an empathogen (entactogen) that mainly enhances positive feelings, empathy, and prosociality (Hysek et al, 2014a; Kirkpatrick et al, 2014) while having few hallucinogen-like effects. Additionally, MDMA has been shown to positively alter emotion processing (Bedi et al, 2010; Hysek et al, 2012,2014a; Kirkpatrick et al, 2012,2014; Schmid et al, 2014). These acute effects of MDMA on emotion processing and social behavior may be beneficial during psychotherapy in the absence of a full psychedelic peak experience. LSD also produced acute MDMA-like subjective effects, including greater well-being, happiness, closeness to others, openness, and trust (Schmid et al, 2015). Thus, LSD and MDMA may have common effects on the processing of emotional information with relevance to their positive acute and possibly long-term effects during psychotherapy. However, the effects of LSD in tests of emotion processing are unknown. Therefore, the present study investigated the acute effects of LSD using the Face Emotion Recognition Task (FERT) and Multifaceted Empathy Test (MET). The effects of LSD on social behavior were also evaluated using the Social Value Orientation (SVO) test. Additionally, we assessed the subjective mood effects of LSD using Visual Analog Scales (VASs) and the Adjective Mood Rating Scale (AMRS), vital signs, and adverse effects. We hypothesized that LSD would impair the recognition of negative emotions on the FERT and enhance emotional empathy on the MET and prosociality on the SVO test.

\section{MATERIALS AND METHODS}

\section{Study Design}

We pooled data from two similar studies using double-blind, placebo-controlled, crossover designs with two experimental test sessions (LSD and placebo) in a balanced order. Study 1 used a dose of $100 \mu \mathrm{g}$ LSD and placebo in 24 subjects. Study 2 used $200 \mu \mathrm{g}$ LSD or placebo in 16 subjects. The washout periods between sessions were at least 7 days. The studies were conducted in accordance with the Declaration of Helsinki and approved by the local ethics committee. The administration of LSD to healthy subjects was authorized by the Swiss Federal Office for Public Health, Bern, Switzerland. All of the subjects provided written consent before participating in either of the studies, and they were paid for their participation. The studies were registered at ClinicalTrials.gov (NCT02308969, NCT01878942). The subjective, endocrine, and pharmacokinetic effects of LSD in Study 2 were previously reported (Dolder et al, 2015b; Schmid et al, 2015; Strajhar et al, 2016).

\section{Participants}

Forty healthy participants were recruited from the University of Basel campus via online advertisement. Twenty-four subjects (12 men, 12 women; $33 \pm 11$ years old (mean $\pm S D$ ); range, $25-60$ years) participated in Study 1 , and 16 subjects (8 men, 8 women; $29 \pm 6$ years old; range, $25-51$ years) participated in Study 2. The inclusion and exclusion criteria were identical for both studies. Subjects younger than 25 years of age were excluded from participating in the study. Additional exclusion criteria were age $>65$ years, pregnancy (urine pregnancy test at screening and before each test session), personal or family (first-degree relative) history of major psychiatric disorders (assessed by the semistructured clinical interview for Diagnostic and Statistical Manual of Mental Disorders, 4th edition, Axis I disorders by the study physician and an additional interview by a trained psychiatrist), use of medications that may interfere with the study medication, chronic or acute physical illness (abnormal physical exam, electrocardiogram, or hematological and chemical blood analyses), tobacco smoking ( $>10$ cigarettes/day), lifetime prevalence of illicit drug use $>10$ times (except for tetrahydrocannabinol), illicit drug use within the last 2 months, and illicit drug use during the study (determined by urine drug tests). The subjects were asked to abstain from excessive alcohol consumption between test sessions and particularly limit their use to one standard drink on the day before the test sessions. Additionally, the participants were not allowed to drink xanthine-containing liquids after midnight before the study day. Eleven subjects had used a hallucinogen including LSD (6 participants) one to three times, and most of the subjects (29) were hallucinogen-naïve (Supplementary Table S1). We performed urine drug tests at screening and before each test session, and no substances were detected during the study.

\section{Study Procedures}

Each study included a screening visit, a psychiatric interview, two 25-h experimental sessions, and an end-of-study visit. The experimental sessions were conducted in a quiet standard hospital patient room. The participants were resting in hospital beds except when going to the restroom. Only one research subject and one investigator were present during the experimental sessions. Participants could interact with the investigator, rest quietly and/or listen to music via headphones, but no other entertainment was provided. LSD or placebo was administered at 0900 hours. The subjects were never alone during the first $12 \mathrm{~h}$ after drug administration, and the investigator was in a room next to the subject for up to $24 \mathrm{~h}$ while subjects were asleep (mostly from 0100 to 0800 hours). Because subjective responses to LSD are pronounced and peak at $2-3 \mathrm{~h}$ and last up to $12 \mathrm{~h}$ (Passie et al, 2008; Schmid et al, 2015), effects on emotion processing and prosociality were assessed 5 and $7 \mathrm{~h}$ after the 100 and $200 \mu \mathrm{g}$ doses, respectively, when the subjective effects of LSD amounted to approximately $50 \%$ of the peak responses (Dolder et al, 2015b; Schmid et al, 2015).

\section{Study Drug}

LSD (D-LSD hydrate; Lipomed AG, Arlesheim, Switzerland) was administered in single oral doses of 100 or $200 \mu \mathrm{g}$. Both doses are within the range of doses that are taken for recreational purposes (Passie et al, 2008).

\section{Measures}

Facial Emotion Recognition Task. We used the FERT, which is sensitive to the effects of other psychoactive 
substances, including serotonin and norepinephrine uptake inhibitors (Harmer et al, 2004), MDMA (Bedi et al, 2010; Hysek et al, 2014b; Kirkpatrick et al, 2014; Schmid et al, 2014), and methylphenidate (Hysek et al, 2014b; Schmid et al, 2014). The task included 10 neutral faces and 160 faces that expressed one of four basic emotions (ie, happiness, sadness, anger, and fear), with pictures morphed between $0 \%$ (neutral) and $100 \%$ in $10 \%$ steps. Two female and two male pictures were used for each of the four emotions. The stimuli were presented in random order for $500 \mathrm{~ms}$ and then were replaced by the rating screen where participants had to indicate the correct emotion. The outcome measure was accuracy (proportion correct). The FERT was performed 5 and $7 \mathrm{~h}$ after the 100 and $200 \mu \mathrm{g}$ doses of LSD, respectively.

Multifaceted Empathy Test. The MET is a reliable and valid task that assesses the cognitive and emotional aspects of empathy (Dziobek et al, 2008). The MET has been shown to be sensitive to oxytocin (Hurlemann et al, 2010), MDMA (Hysek et al, 2014a; Kuypers et al, 2014; Schmid et al, 2014), and psilocybin (Preller et al, 2015). The computer-assisted test consisted of 40 photographs that showed people in emotionally charged situations. To assess cognitive empathy, the participants were required to infer the mental state of the subject in each scene and indicate the correct mental state from a list of four responses. Cognitive empathy was defined as the percentage of correct responses relative to total responses. To measure emotional empathy, the subjects were asked to rate how much they were feeling for an individual in each scene (ie, explicit emotional empathy) and how much they were aroused by each scene (ie, implicit emotional empathy) on a 1-9 point scale. The latter rating provides an inherent additional assessment of emotional empathy, which is considered to reduce the likelihood of socially desirable answers. The three aspects of empathy were each tested with 20 stimuli with positive valence and 20 stimuli with negative valence, resulting in a total of 120 trials. The MET was performed $5 \mathrm{~h}$ and $30 \mathrm{~min}$ after the $100 \mu \mathrm{g}$ LSD dose and $7 \mathrm{~h}$ and $30 \mathrm{~min}$ after the $200 \mu \mathrm{g}$ LSD, respectively.

SVO test. We used the paper version of the validated SVO test to assess social behavior (Murphy et al, 2011). The SVO measure was previously shown to be sensitive to MDMA (Hysek et al, 2014a). In this economic resource allocation task, prosociality is defined as behavior that maximizes the sum of resources for the self and others and minimizes the difference between the two. The test consists of six primary and nine secondary SVO slider items with a resource allocation choice over a defined continuum of joint payoffs (Murphy et al, 2011). The participants were instructed to choose a resource allocation that defined their most preferred joint distribution between themselves and another person. The allocated funds had real value, and four randomly selected subjects received the funds they earned. Mean allocations for the self and the other were calculated (Hysek et al, 2014a; Murphy et al, 2011), and the inverse tangent of the ratio of these two means produced an angle that indicated the participants' SVO index. A smaller SVO angle indicates more individualistic or competitive behavior, and a larger SVO angle indicates more prosocial or even altruistic behavior. The SVO was performed 6 and $8 \mathrm{~h}$ after the 100 and $200 \mu \mathrm{g}$ doses of LSD, respectively.

Subjective mood. The VASs and the AMRS (Janke and Debus, 1978) were repeatedly used to assess subjective effects including aspects of empathy and sociality (Hysek et al, 2014a; Schmid et al, 2015) (Supplementary Material and Methods).

Vital signs and adverse effects. Blood pressure, heart rate, body temperature, pupil diameter, and adverse effects were measured as described in the Supplementary Material and Methods.

Drug concentrations. Blood samples for the analysis of plasma LSD levels were collected in lithium heparin tubes after completing the social cognitive tests 6 and $8 \mathrm{~h}$ after administration of the 100 and $200 \mu \mathrm{g}$ doses of LSD or placebo, respectively. Plasma LSD concentrations were determined using liquid-chromatography tandem mass spectrometry (Dolder et al, 2015a).

\section{Statistical Analyses}

All of the data were analyzed using repeated measures analysis of variance (ANOVA), with drug (LSD vs placebo) as the within-subjects factor and dose $(100 v s 200 \mu \mathrm{g})$ as the between-subjects factor, followed by the Tukey's post hoc test based on significant main effects or interactions. Repeated subjective measures were expressed as peak effects prior to the ANOVAs. Additionally, differences at individual time points were also compared using paired $t$-tests. Modulatory effects by sex or previous hallucinogen use were excluded by adding sex or substance use as an additional factor to the ANOVAs. Sex or previous substance use did not moderate outcome measures.

\section{RESULTS}

\section{Facial Emotion Recognition}

The effects of LSD on the FERT are shown in Figure 1. Data were missing from 2 of the 24 subjects in the $100 \mu \mathrm{g}$ LSD dose group because of technical problems. LSD impaired the recognition of fearful faces (main effect of drug: $F_{1,36}=20.71$, $p<0.001$ ), with no drug $\times$ dose interaction. Impairments were found in both the 100 and $200 \mu \mathrm{g}$ dose groups compared with placebo ( $p<0.01$ and $p<0.05$, respectively). A significant main effect of drug $\left(\mathrm{F}_{1,36}=7.36, p=0.01\right)$ indicated that LSD also impaired the recognition of sad faces, but post hoc comparisons of the two dose groups with placebo did not reach significance. No significant effects of LSD on the decoding of neutral, happy, or angry facial expressions were found.

\section{Empathy}

The effects of LSD on explicit emotional and cognitive empathy are shown in Figure 2. Data were missing from 2 of the 24 subjects in the $100 \mu \mathrm{g}$ LSD dose group because of technical problems. There were significant main effects of drug on explicit and implicit emotional empathy ratings 

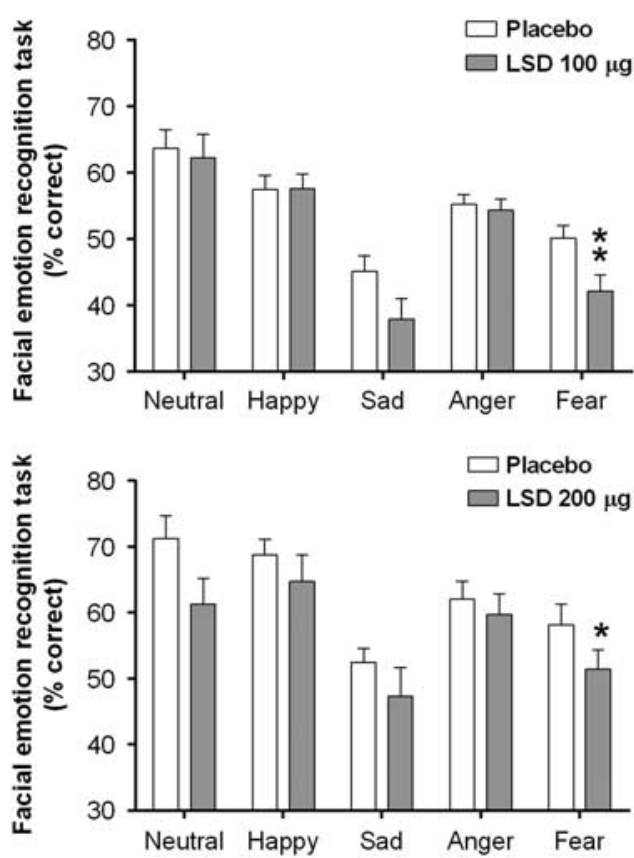

Figure I Lysergic acid diethylamide (LSD) impaired fear recognition on the Face Emotion Recognition Task. LSD also impaired the decoding of sad faces (significant main effect of drug), but the effects did not reach statistical significance in the individual dose groups. The data are expressed as mean \pm SEM in 22 and 16 subjects in the 100 and $200 \mu \mathrm{g}$ LSD dose groups, respectively. ${ }^{*} p<0.05,{ }^{*} * p<0.0$ I, significant difference from placebo.

$\left(\mathrm{F}_{1,36}=14.05, p<0.001\right.$ and $\mathrm{F}_{1,36}=6.71, p=0.01$, respectively), indicating that LSD increased both aspects of emotional empathy. The post hoc tests showed that the $200 \mu \mathrm{g}$ dose but not the $100 \mu \mathrm{g}$ dose of LSD produced a significant effect on explicit $(p<0.01)$ and implicit $(p=0.01)$ empathy scores compared with placebo. The valence-specific analysis showed that LSD significantly increased explicit and implicit emotional empathy scores for positive emotional stimuli $\left(\mathrm{F}_{1,36}=24.32, p<0.001\right.$ and $\mathrm{F}_{1,36}=10.47, p<0.01$, respectively) but there were only trend effects for negative emotional stimuli $\left(\mathrm{F}_{1,36}=3.29, p=0.08\right.$ and $\mathrm{F}_{1,36}=2.82$, $p=0.1$, respectively). LSD decreased cognitive empathy, reflected by a significant main effect of drug $\left(\mathrm{F}_{1,36}=16.87\right.$, $p<0.001)$. The post hoc tests showed that this effect was significant for both the 100 and $200 \mu \mathrm{g}$ doses compared with the respective placebo conditions (both $p<0.05$ ).

\section{Social Value Orientation}

A significant effect of drug was found on the SVO angle $\left(\mathrm{F}_{1,38}=4.31, p<0.05\right)$, indicating that LSD increased prosociality. The post hoc tests showed that this effect did not reach significance in the individual LSD dose groups and was only evident in the larger total study sample.

\section{Subjective Mood Effects}

Subjective effects on the VASs are shown in Figure 3, and maximal values are presented in Table 1 . LSD increased maximal VAS rating scores, including those reflecting empathy and prosociality such as 'feeling close to others', 'open', 'trust', and 'I want to be with others', with greater
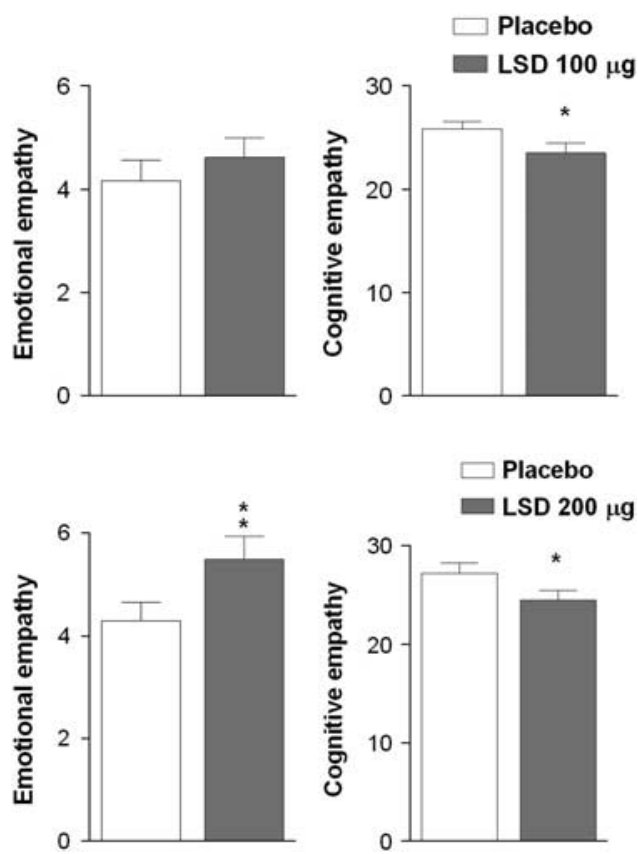

Figure 2 Lysergic acid diethylamide (LSD) increased emotional empathy and decreased cognitive empathy on the Multifaceted Empathy Test. The data are expressed as mean \pm SEM in 22 and 16 subjects in the 100 and $200 \mu \mathrm{g}$ LSD dose groups, respectively. ${ }^{*} p<0.05$, ${ }^{*} * x<0.0$ I, significant difference from placebo.

peak effects at the higher compared with the lower dose. Ratings of 'happy' were similarly increased by both doses. LSD produced small dose-dependent increases in 'bad drug effect' and 'fear' (Figure 3, Table 1). On the AMRS, LSD significantly increased ratings of 'well-being', 'emotional excitation', 'inactivity', 'introversion', and 'dreaminess' compared with placebo (Figure 4 and Table 1). There was a significant main effect of LSD on 'fear' but no significant effects in the individual studies.

\section{Vital Signs and Adverse Effects}

Peak values and statistics are shown in Table 1. Compared with placebo, LSD increased blood pressure, heart rate, and body temperature as well as pupil size in the dark and after a light stimulus (Table 1). These effects were similar for both doses (no drug $\times$ dose interaction). Compared with placebo, both doses of LSD increased the total acute $(0-10 \mathrm{~h})$ adverse effects. Only the high dose increased the total subacute (10-24h) adverse effects. Adverse effects $24-72 \mathrm{~h}$ were slightly increased in the total sample but not in the individual studies (Table 1). The frequently reported adverse effects are presented in Supplementary Table S2. There were no severe adverse events.

\section{Plasma Drug Levels and Correlations Between Effects}

Plasma concentrations of LSD were $0.7 \pm 0.3 \mathrm{ng} / \mathrm{ml}($ mean \pm SD) $6 \mathrm{~h}$ after administration of the $100 \mu \mathrm{g}$ dose and $1.3 \pm 0.6 \mathrm{ng} / \mathrm{ml}$ $8 \mathrm{~h}$ after administration of the $200 \mu \mathrm{g}$ dose. These time points of blood sample collection were immediately after the social cognitive tests performed in the respective dose groups. Plasma 

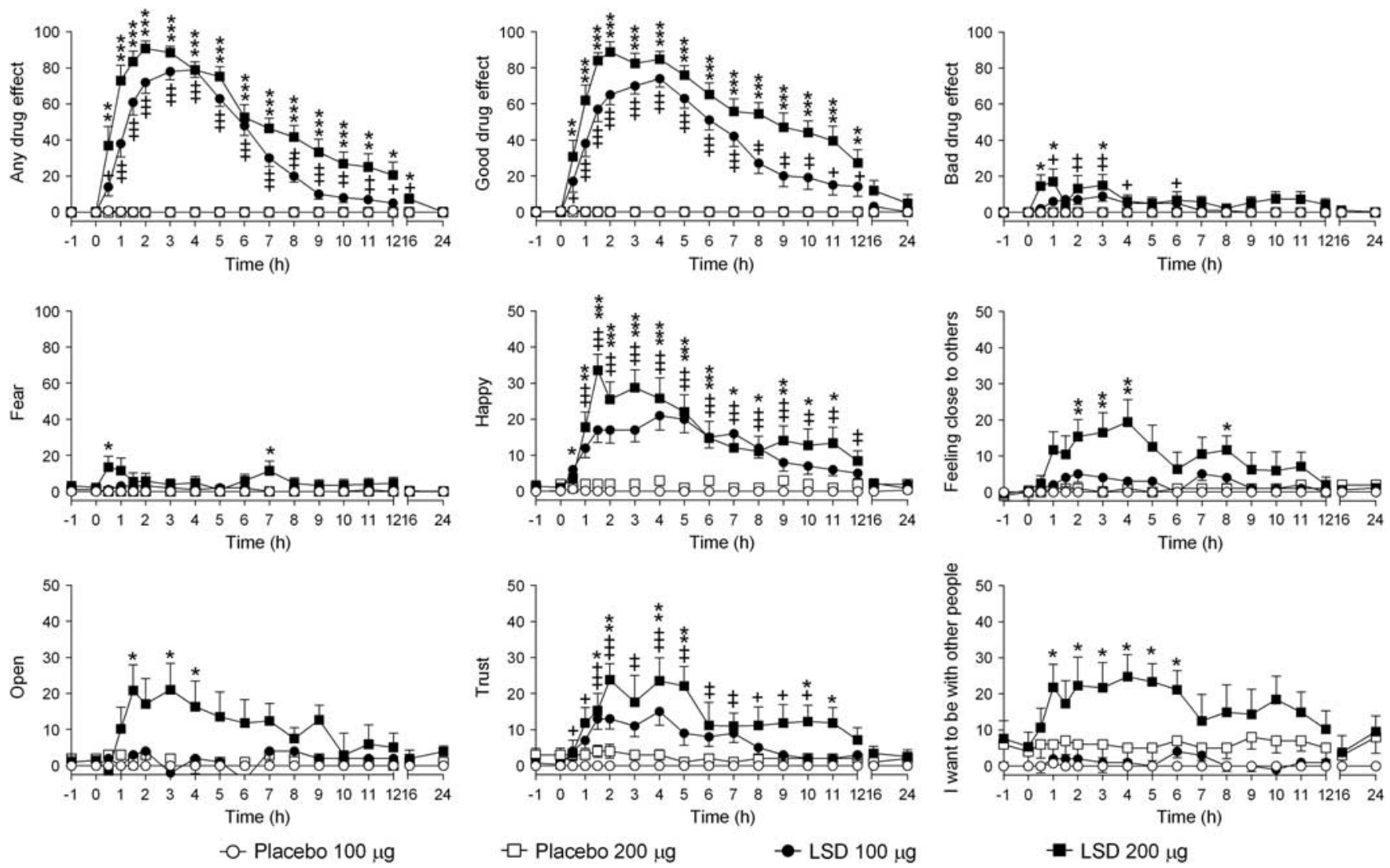

Figure 3 Subjective effects of lysergic acid diethylamide (LSD) over time on the Visual Analog Scales (VASs). LSD or placebo was administered at $t=0$. The data are expressed as mean \pm SEM in 24 and 16 subjects in the 100 and $200 \mu \mathrm{g}$ LSD dose groups, respectively. LSD significantly increased ratings on all VASs with significant dose-response effects, except for ratings of 'happy'. The corresponding maximal effects and statistics are shown in Table I. Emotion recognition (Face Emotion Recognition Task), empathy (Multifaceted Empathy Test), and social value orientation (SVO) tests were conducted 5-6 and 7-8 $\mathrm{h}$ after the administration of the 100 and $200 \mu \mathrm{g}$ LSD dose, respectively. $+/ * p<0.05,++/ * * * 2<0.01,+++/ * * * *<0.00$ I for the I00/200 $\mu \mathrm{g}$ LSD dose, respectively, compared with placebo (T-tests).

LSD levels correlated with explicit emotional empathy scores on the MET for positive (Spearman $R_{\mathrm{s}}=0.37, p<0.05, n=38$ ) but not for negative emotional situations. Plasma levels of LSD were not associated with FERT or SVO test measures. Plasma levels of LSD were associated with LSD-induced ratings of trust (Spearman $R_{\mathrm{s}}=0.32, p<0.05, n=40$ ). LSD-induced VAS ratings for feelings of 'closeness' and 'trust' were associated with greater explicit empathy for positive emotional stimuli (Spearman $R_{\mathrm{s}}=0.35, p<0.05$ and $R_{\mathrm{s}}=0.47, p<0.01$, respectively, $n=38$ ).

\section{DISCUSSION}

LSD positively altered the processing of emotional information by decreasing the recognition of fearful and sad faces and enhancing emotional empathy and prosociality. We are aware of no other published data on the acute effects of LSD on emotion processing. However, MDMA produced very similar effects to those of LSD in the present study. MDMA reduced the recognition of sad and fearful faces but not happy faces on the FERT (Bedi et al, 2010; Hysek et al, 2014b), increased explicit and implicit emotional empathy on the MET (Hysek et al, 2014a; Kuypers et al, 2014) (mainly for positive emotionally charged situations) (Hysek et al, 2014a;
Schmid et al, 2014), and increased prosociality on the SVO test (Hysek et al, 2014a). LSD did not facilitate perception of happiness in the FERT similar to MDMA (Bedi et al, 2010; Hysek et al, 2014b), possibly because detection of positive basic emotions is very accurate in healthy subjects and difficult to enhance. Thus, the $5-\mathrm{HT}_{2 \mathrm{~A}}$ receptor agonist LSD and 5-HT releaser MDMA may produce overall similar effects on the processing of emotional information. However, in contrast to MDMA, LSD also impaired cognitive empathy on the MET, and the higher dose also decreased the recognition of neutral faces on the FERT, indicating nonspecific performance effects. Similar to LSD, the $5-\mathrm{HT}_{2 \mathrm{~A}}$ receptor agonist psilocybin decreased the recognition of negative facial expressions (Kometer et al, 2012) and increased emotional empathy on the MET (Preller et al, 2015). Altogether, these findings indicate that LSD affects emotion processing similarly to MDMA and psilocybin.

The marked acute psychedelic/hallucinogenic 'peak response' to LSD and psilocybin has been considered relevant to their lasting effects (Carhart-Harris et al, 2016; Griffiths et al, 2011). The present study showed that LSD has dose-dependent subjective effects on empathogenic mood, including 'feelings of closeness to others', 'wanting to be with others', 'happiness,' 'openness,' and 'trust' (Schmid et al, 2015), in addition to more hallucinogen-specific 
Table I Values and Statistics for the Subjective and Cardiovascular Peak Effects

\begin{tabular}{|c|c|c|c|c|c|c|c|c|}
\hline & \multirow{2}{*}{$\begin{array}{l}\text { Placebo } 100 \mu \mathrm{g} \\
(\text { mean } \pm \mathrm{SE})\end{array}$} & \multirow{2}{*}{$\begin{array}{l}\text { LSD } 100 \mu g \\
(\text { mean } \pm \text { SE })\end{array}$} & \multirow{2}{*}{$\begin{array}{l}\text { Placebo } 200 \mu \mathrm{g} \\
(\text { mean } \pm \text { SE })\end{array}$} & \multirow{2}{*}{$\begin{array}{l}\text { LSD } 200 \mu g \\
(\text { mean } \pm \text { SE })\end{array}$} & \multicolumn{2}{|c|}{ Drug } & \multicolumn{2}{|c|}{ Drug $\times$ Dose } \\
\hline & & & & & $\mathbf{F}_{1,38}=$ & $p=$ & $\mathbf{F}_{1,38}=$ & $p=$ \\
\hline \multicolumn{9}{|l|}{ Subjective effects } \\
\hline \multicolumn{9}{|l|}{ Visual Analog Scales (VAS, \%) } \\
\hline Any drug effect & $0.9 \pm 0.6$ & $87.5 \pm 3.3$ ***** & $0.1 \pm 0.1$ & $97.2 \pm 1.7 * * * \#$ & 1939 & ***** & 6.21 & $*$ \\
\hline Fear & $0.0 \pm 0.0$ & $8.4 \pm 2.3$ & $0.06 \pm 0.1$ & $31.3 \pm 8.6 * * * \# \# \#$ & 27.74 & ***** & 9.24 & **⿻丷木 \\
\hline Happy & $1.2 \pm 0.6$ & $30 \pm 3.4 * * * * *$ & $5.0 \pm 2.0$ & $39.1 \pm 4.2 * * * *$ & $14 \mid .5$ & 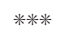 & I & NS \\
\hline Closeness to others & $0.0 \pm 0.0$ & $15.2 \pm 3.2 *$ ***** & $4.3 \pm 1.8$ & $32.3 \pm 4.7 * * * \# \# \#$ & 61.68 & ****** & 5.38 & $*$ \\
\hline Open & $0.2 \pm 0.2$ & $17.0 \pm 2.8 * * * * *$ & $3.9 \pm 1.5$ & $41.0 \pm 3.6 * * * \# \# \#$ & 128.9 & ***** & 18.4 & ***** \\
\hline Trust & $0.0 \pm 0.0$ & $22.0 \pm 4.1$ 米米米 & $4.8 \pm 2.1$ & $39.8 \pm 4.0 * * * \# \# \#$ & 81.37 & ****** & 4.2 & $*$ \\
\hline I want to be with other people & $0.8 \pm 0.8$ & $12.8 \pm 2.5 * *$ & $10.8 \pm 4.2$ & $42.8 \pm 5.5 * * * \# \# \#$ & 79.87 & ***** & 16.25 & **** \\
\hline \multicolumn{9}{|l|}{ Adjective Mood Rating Scale (AMRS, $\Delta$ score) } \\
\hline Well-being & $0.0 \pm 0.6$ & $2.5 \pm 1.0$ & $1.8 \pm 0.7$ & $6.6 \pm 1.6 *$ & 11.49 & *** & I.I1 & NS \\
\hline Emotional excitation & $-0.3 \pm 0.2$ & $2.3 \pm 0.5 * *$ & $-0.3 \pm 0.3$ & $4.7 \pm 1.0 * * * \# \#$ & 53.5 & ****** & 4.77 & $*$ \\
\hline Inactivity & $2.6 \pm 0.7$ & $9.0 \pm 1.1 * * *$ & $1.3 \pm 1.1$ & $10.6 \pm 2.7 * * * *$ & 30.82 & 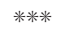 & 1.05 & NS \\
\hline Extroversion & $-0.5 \pm 0.3$ & $-0.1 \pm 0.6$ & $0.1 \pm 0.5$ & $1.5 \pm 0.7$ & 2.67 & NS & 0.77 & NS \\
\hline Introversion & $0.4 \pm 0.1$ & $4.1 \pm 0.6 * * * *$ & $0.5 \pm 0.4$ & $4.3 \pm 0.8 * * * *$ & 51.92 & ***** & 0.01 & NS \\
\hline Fear & $-0.1 \pm 0.1$ & $0.9 \pm 0.3$ & $-0.4 \pm 0.3$ & $1.3 \pm 1.0$ & 9.51 & *** & 0.72 & NS \\
\hline Dreaminess & $0.2 \pm 0.3$ & $6.9 \pm 0.7^{* * * * *}$ & $0.8 \pm 0.5$ & $7.9 \pm 0.6 * * * *$ & 160.2 & ****** & 0.11 & NS \\
\hline \multicolumn{9}{|l|}{ Vital signs } \\
\hline Pupil size $(\mathrm{mm})$ & $6.1 \pm 0.2$ & $6.9 \pm 0.1 * * * * *$ & $6.5 \pm 0.2$ & $7.2 \pm 0.1 * * * *$ & 61.08 & 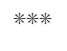 & 0.81 & NS \\
\hline Pupil size after light (mm) & $4.3 \pm 0.2$ & $5.2 \pm 0.2 * * * * *$ & $4.6 \pm 0.2$ & $5.6 \pm 0.2 * * * *$ & 89.61 & ****** & 0.02 & NS \\
\hline \multicolumn{9}{|l|}{ List of complaints ( $\Delta$ LC total score) } \\
\hline Acute adverse effects $(0-10$ h) & $0.5 \pm 0.3$ & $9.8 \pm 1.8^{* * * * *}$ & $0.1 \pm 0.6$ & $10.4 \pm 3.0 * * *$ & 38.37 & 米米米 & 0 & NS \\
\hline Subacute adverse effects ( $10-24$ h) & $-0.2 \pm 0.3$ & $0.4 \pm 0.2$ & $-0.4 \pm 0.4$ & $3.7 \pm 1.4 * *$ & 12.06 & *** & 6.76 & * \\
\hline Subacute adverse effects (24-72 h) & $-0.5 \pm 0.3$ & $-0.1 \pm 0.2$ & $-0.8 \pm 0.4$ & $0.6 \pm 0.9$ & 6.03 & $*$ & 1.83 & NS \\
\hline
\end{tabular}

Values are mean \pm SEM of the peak or peak changes $(\Delta)$ from baseline in 40 subjects. Sixteen subjects participated in the high dose study (200 $\mu \mathrm{g})$ and 24 subjects in the moderate dose study $(100 \mu \mathrm{g})$.

*for $p<0.05$, *** for $p<0.01$, ***** for $p<0.00$ I compared with placebo. \# for $p<0.05$, \#\# for $p<0.01$, \#\#\# for $p<0.00$ I compared with LSD I00 $\mu$ g.

psychedelic peak effects. These acute subjective effects of LSD and its effects on the emotion processing and behavioral tests in the present study are very similar to those of the prototypic empathogen MDMA. However, LSD induced higher AMRS intro- than extroversion while MDMA produced more extro- than introversion (Hysek et al, 2014a). Importantly, the subjective feelings of 'happiness', 'trust', 'closeness to others', and 'desire to be with others' at the high dose of LSD were maintained up to 6-12 h, and the effects of LSD on emotion processing and prosociality were also observed late in time at 6-8 $\mathrm{h}$ after LSD administration and after the peak response when a 'plateau phase' was reached. At that time, the subjects were also less overwhelmed by initially strong and mostly novel psychedelic experiences, which may open a window for psychotherapeutic interventions. The emotional effects during the later phase of the acute LSD response (6-10 h) are likely beneficial to acutely facilitating the therapeutic alliance. Future research should address the relative contributions of the psychedelic peak experience $v s$ empathogenic 

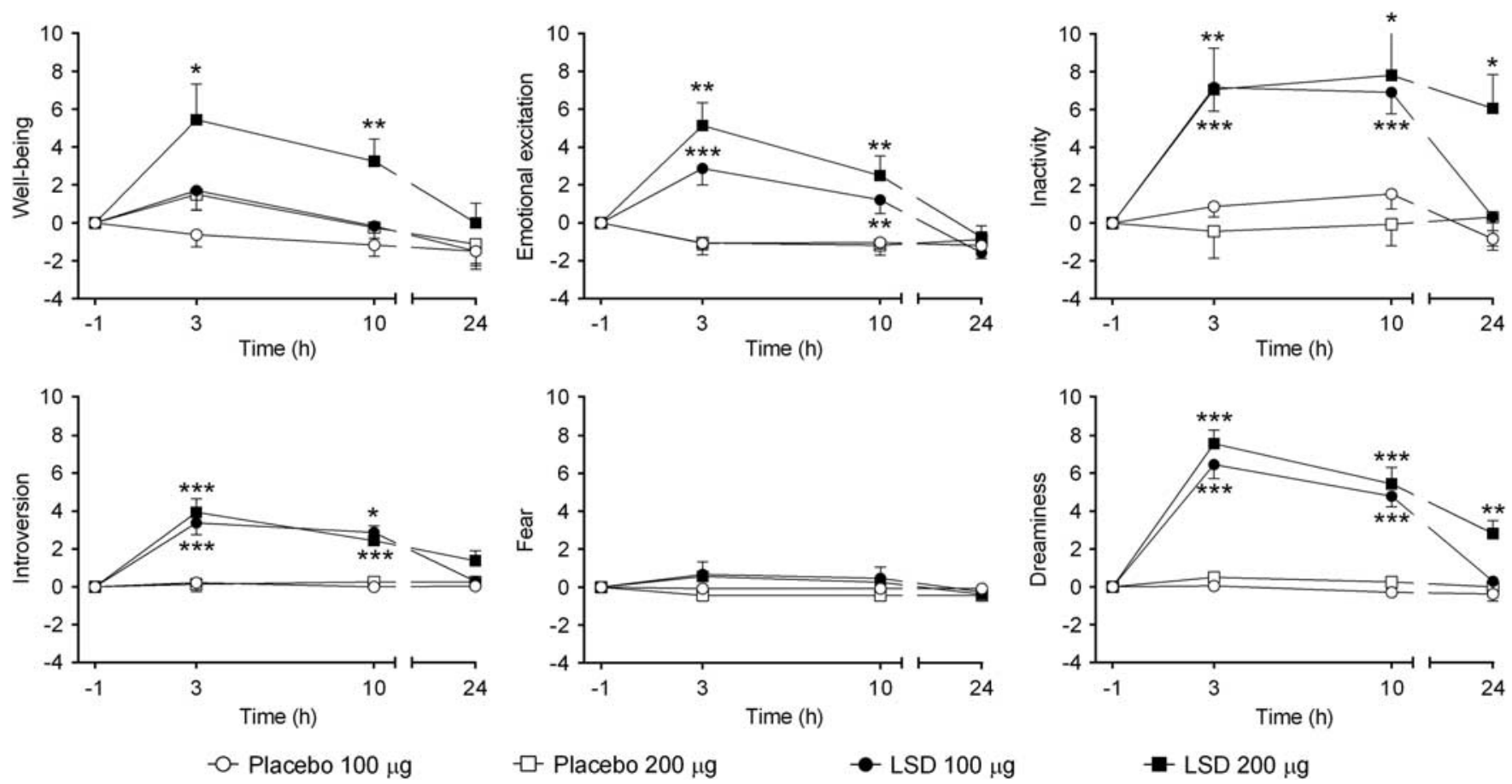

Figure 4 Subjective effects on the Adjective Mood Rating Scale. Lysergic acid diethylamide (LSD) or placebo was administered at $t=0$. The data are expressed as mean \pm SEM changes from baseline $(-1 \mathrm{~h})$ in 24 and 16 subjects in the 100 and $200 \mu \mathrm{g}$ LSD dose groups, respectively. Emotion recognition (Face Emotion Recognition Task), empathy (Multifaceted Empathy Test), and social value orientation (SVO) tests were conducted 5-6 and 7-8 h after the administration of the 100 and $200 \mu \mathrm{g}$ LSD dose, respectively. The corresponding maximal effects and statistics are shown in Table I. *p $<0.05$, *** $<0.0$ I, ***** $p<0.00$ I compared with placebo (T-tests).

emotional effects of LSD to its potential therapeutic effects. Additionally, it seems that only the higher $200 \mu \mathrm{g}$ dose of LSD produced robust empathogenic effects. Furthermore, the relevance of deficits in cognitive empathy for the therapeutic process is unclear.

The present study also showed that LSD was well tolerated in a controlled setting in healthy subjects. Adverse effects of LSD mainly included acute dizziness, headache, and fatigue/ exhaustion lasting up to $72 \mathrm{~h}$. Both doses of LSD produced comparable moderate sympathomimetic effects including elevated blood pressure, heart rate, body temperature, and mydriasis.

The present study used two doses of LSD within a clinically relevant dose range. In fact, the higher dose was identical to both the amount and pharmaceutical formulation that were used in a clinical study in patients with anxiety (Gasser et al, 2014) and continue to be used in patients in Switzerland. Additionally, LSD was administered to subjects across a relatively wide age range (25-60 years). Importantly, the subjects typically had no or very limited hallucinogen experience, which is possibly similar to cases in which LSD is used therapeutically in patients. In contrast, other contemporary studies used lower doses of LSD in subjects with extensive prior substance use (Carhart-Harris et al, 2016,2015). However, in the present study, previous hallucinogen use (1-3 times including LSD in six subjects) did not alter the responses to LSD.

In the present study, the tests were performed approximately $3 \mathrm{~h}$ after the peak effects (Dolder et al, 2015b; Schmid et al, 2015). At the time of the peak response of LSD, test administration would not have been feasible because of the strong alterations in wake consciousness and impairments in concentration (Schmid et al, 2015). The participants needed to adjust to the altered state of consciousness; therefore, testing occurred after a 'plateau phase' was reached. Nevertheless, at the time of testing, the subjective effects and plasma concentrations of LSD were still at approximately $50 \%$ of the peak responses and clearly effective in producing typical LSD effects, providing a good time interval for conducting the neurocognitive tasks (Carhart-Harris et al, 2016; Schmid et al, 2015). Additionally, the tests were performed later after the high dose than after the low dose of LSD. However, at the times of testing, plasma LSD concentrations were twice as high after the $200 \mu \mathrm{g}$ dose compared with the $100 \mu \mathrm{g}$ dose, and generating a dose/concentration-response effect was possible.

The study has limitations. First, the dose effects of LSD were studied in different participants and not within-subject. Second, we assessed only emotion recognition and no other measures such as face muscle responses to emotions (Wardle et al, 2014) and the stimuli were artificial (pictures) rather than real people. With regard to the use of LSD in psychotherapy, we only assessed 'empathic concern for others' but not whether the participants 'felt cared for or understood by someone else' (Wardle and de Wit, 2014). It is possible that LSD affected attention and motivation and thereby task performance. Thus, it will be important to replicate and expand our findings using additional emotion recognition tests (Wardle and de Wit, 2014), tests of responses to emotions (Wardle and de Wit, 2014; Wardle et al, 2014), and other measures of social interaction (Frye et al, 2014). 
In conclusion, LSD impaired emotion recognition of negative emotions and enhanced emotional empathy, particularly for positive emotional situations, and had subjective and behaviorally tested prosocial effects. These effects of LSD in healthy participants likely have translational relevance to LSD-assisted psychotherapy in patients and can be expected to reduce the perception of negative emotions and facilitate the therapeutic alliance.

\section{FUNDING AND DISCLOSURE}

This work was supported by the Swiss National Science Foundation (grant no. 320030_1449493 to MEL) and the University of Basel (to FM). The authors declare no conflict of interest.

\section{ACKNOWLEDGMENTS}

We acknowledge the assistance of $M$ Arends in text editing. The studies were registered at ClinicalTrials.gov (NCT02308969, NCT01878942).

\section{REFERENCES}

Bedi G, Hyman D, de Wit H (2010). Is ecstasy an 'empathogen'? Effects of \pm 3,4-methylenedioxymethamphetamine on prosocial feelings and identification of emotional states in others. Biol Psychiatry 68: 1134-1140.

Bogenschutz MP, Forcehimes AA, Pommy JA, Wilcox CE, Barbosa PC, Strassman RJ (2015). Psilocybin-assisted treatment for alcohol dependence: a proof-of-concept study. J Psychopharmacol 29: 289-299.

Carhart-Harris RL, Kaelen M, Bolstridge M, Williams TM, Williams LT, Underwood R et al (2016). The paradoxical psychological effects of lysergic acid diethylamide (LSD). Psychol Med 46: 1379-1390.

Carhart-Harris RL, Kaelen M, Whalley MG, Bolstridge M, Feilding A, Nutt DJ (2015). LSD enhances suggestibility in healthy volunteers. Psychopharmacology 232: 785-794.

Dolder PC, Liechti ME, Rentsch KM (2015a). Development and validation of a rapid turboflow LC-MS/MS method for the quantification of LSD and 2-oxo-3-hydroxy LSD in serum and urine samples of emergency toxicological cases. Anal Bioanal Chem 407: 1577-1584.

Dolder PC, Schmid Y, Haschke M, Rentsch KM, Liechti ME (2015b). Pharmacokinetics and concentration-effect relationship of oral LSD in humans. Int J Neuropsychopharmacol (doi:10.1093/ijnp/pyv072).

Dziobek I, Rogers K, Fleck S, Bahnemann M, Heekeren HR, Wolf OT et al (2008). Dissociation of cognitive and emotional empathy in adults with Asperger syndrome using the Multifaceted Empathy Test (MET). J Autism Dev Disord 38: 464-473.

Frye CG, Wardle MC, Norman GJ, de Wit H (2014). MDMA decreases the effects of simulated social rejection. Pharmacol Biochem Behav 117: 1-6.

Gasser P, Holstein D, Michel Y, Doblin R, Yazar-Klosinski B, Passie $\mathrm{T}$ et al (2014). Safety and efficacy of lysergic acid diethylamide-assisted psychotherapy for anxiety associated with life-threatening diseases. J Nerv Ment Dis 202: 513-520.

Gasser P, Kirchner K, Passie T (2015). LSD-assisted psychotherapy for anxiety associated with a life-threatening disease: a qualitative study of acute and sustained subjective effects. J Psychopharmacol 29: $57-68$.

Griffiths RR, Johnson MW, Richards WA, Richards BD, McCann U, Jesse R (2011). Psilocybin occasioned mystical-type experiences: immediate and persisting dose-related effects. Psychopharmacology 218: 649-665.

Griffiths RR, Richards WA, McCann U, Jesse R (2006). Psilocybin can occasion mystical-type experiences having substantial and sustained personal meaning and spiritual significance. Psychopharmacology 187: 268-283 discussion 284-292.

Grob CS, Danforth AL, Chopra GS, Hagerty M, McKay CR, Halberstadt AL et al (2011). Pilot study of psilocybin treatment for anxiety in patients with advanced-stage cancer. Arch Gen Psychiatry 68: 71-78.

Harmer CJ, Shelley NC, Cowen PJ, Goodwin GM (2004). Increased positive versus negative affective perception and memory in healthy volunteers following selective serotonin and norepinephrine reuptake inhibition. Am J Psychiatry 161: 1256-1263.

Hurlemann R, Patin A, Onur OA, Cohen MX, Baumgartner T, Metzler S et al (2010). Oxytocin enhances amygdala-dependent, socially reinforced learning and emotional empathy in humans. J Neurosci 30: 4999-5007.

Hysek CM, Domes G, Liechti ME (2012). MDMA enhances 'mind reading' of positive emotions and impairs 'mind reading' of negative emotions. Psychopharmacology 222: 293-302.

Hysek CM, Schmid Y, Simmler LD, Domes G, Heinrichs M, Eisenegger $\mathrm{C}$ et al (2014a). MDMA enhances emotional empathy and prosocial behavior. Soc Cogn Affect Neurosci 9: 1645-1652.

Hysek CM, Simmler LD, Schillinger N, Meyer N, Schmid Y, Donzelli $M$ et al (2014b). Pharmacokinetic and pharmacodynamic effects of methylphenidate and MDMA administered alone and in combination. Int J Neuropsychopharmacol 17: 371-381.

Janke W, Debus G (1978). Die Eigenschaftswörterliste. Hogrefe: Göttingen.

Johnson MW, Garcia-Romeu A, Cosimano MP, Griffiths RR (2014). Pilot study of the $5-\mathrm{HT}_{2 \mathrm{~A}} \mathrm{R}$ agonist psilocybin in the treatment of tobacco addiction. J Psychopharmacol 28: 983-992.

Kirkpatrick MG, Gunderson EW, Perez AY, Haney M, Foltin RW, Hart CL (2012). A direct comparison of the behavioral and physiological effects of methamphetamine and 3,4-methylenedioxymethamphetamine (MDMA) in humans. Psychopharmacology 219: 109-122.

Kirkpatrick MG, Lee R, Wardle MC, Jacob S, de Wit H (2014). Effects of MDMA and intranasal oxytocin on social and emotional processing. Neuropsychopharmacology 39: 1654-1663.

Kometer M, Schmidt A, Bachmann R, Studerus E, Seifritz E, Vollenweider FX (2012). Psilocybin biases facial recognition, goal-directed behavior, and mood state toward positive relative to negative emotions through different serotonergic subreceptors. Biol Psychiatry 72: 898-906.

Kuypers KP, de la Torre R, Farre M, Yubero-Lahoz S, Dziobek I, Van den Bos W et al (2014). No evidence that MDMA-induced enhancement of emotional empathy is related to peripheral oxytocin levels or 5-HT1a receptor activation. PLoS One 9: e100719.

MacLean KA, Johnson MW, Griffiths RR (2011). Mystical experiences occasioned by the hallucinogen psilocybin lead to increases in the personality domain of openness. J Psychopharmacol 25: 1453-1461.

Mithoefer MC, Wagner MT, Mithoefer AT, Jerome I, Doblin R (2010). The safety and efficacy of $\pm 3,4$-methylenedioxymethamphetamine-assisted psychotherapy in subjects with chronic, treatment-resistant posttraumatic stress disorder: the first randomized controlled pilot study. J Psychopharmacol 25: 439-452.

Mithoefer MC, Wagner MT, Mithoefer AT, Jerome L, Martin SF, Yazar-Klosinski B et al (2013). Durability of improvement in post-traumatic stress disorder symptoms and absence of harmful effects or drug dependency after 3,4-methylenedioxymethamphetamine-assisted psychotherapy: a prospective long-term followup study. J Psychopharmacol 27: 28-39.

Murphy RO, Ackermann KA, Handgraaf MJJ (2011). Measuring social value orientation. Judgm Decis Mak 6: 771-781. 
Nichols DE (2016). Psychedelics. Pharmacol Rev 68: 264-355.

Oehen P, Traber R, Widmer V, Schnyder U (2013). A randomized, controlled pilot study of MDMA $( \pm 3,4$-methylenedioxymethamphetamine)-assisted psychotherapy for treatment of resistant, chronic post-traumatic stress disorder (PTSD). J Psychopharmacol 27: 40-52.

Passie T, Halpern JH, Stichtenoth DO, Emrich HM, Hintzen A (2008). The pharmacology of lysergic acid diethylamide: a review. CNS Neurosci Ther 14: 295-314.

Preller KH, Pokorny T, Krähenmann R, Dziobek I, Stämpfli P, Vollenweider FX (2015). The effect of 5-HT2A/1a agonist treatment on social cognition, empathy, and social decisionmaking. Eur Psychiatry 30(Suppl. 1): 22.

Schmid Y, Enzler F, Gasser P, Grouzmann E, Preller KH, Vollenweider FX et al (2015). Acute effects of lysergic acid diethylamide in healthy subjects. Biol Psychiatry 78(8): 544-553.

Schmid Y, Hysek CM, Simmler LD, Crockett MJ, Quednow BB, Liechti ME (2014). Differential effects of MDMA and methylphenidate on social cognition. J Psychopharmacol 28: 847-856.

Strajhar P, Schmid Y, Liakoni E, Dolder PC, Rentsch KM, Kratschmar DV et al (2016). Acute effects of LSD on circulating steroid levels in healthy subjects. J Neuroendocrinol (doi:10.1111/jne.12374).
Vollenweider FX, Vollenweider-Scherpenhuyzen MF, Babler A, Vogel H, Hell D (1998). Psilocybin induces schizophrenia-like psychosis in humans via a serotonin-2 agonist action. Neuroreport 9: 3897-3902.

Wardle MC, de Wit H (2014). MDMA alters emotional processing and facilitates positive social interaction. Psychopharmacology 231: 4219-4229.

Wardle MC, Kirkpatrick MG, de Wit H (2014). 'Ecstasy' as a social drug: MDMA preferentially affects responses to emotional stimuli with social content. Soc Cogn Affect Neurosci 9: 1076-1081.

This work is licensed under a Creative Commons Attribution-NonCommercial-NoDerivs $\quad 4.0$

International License. The images or other third party material in this article are included in the article's Creative Commons license, unless indicated otherwise in the credit line; if the material is not included under the Creative Commons license, users will need to obtain permission from the license holder to reproduce the material. To view a copy of this license, visit http://creativecommons.org/licenses/by-nc-nd/4.0/

(C) The Author(s) 2016

Supplementary Information accompanies the paper on the Neuropsychopharmacology website (http://www.nature.com/npp) 